\title{
Avaliação de desempenho dos treinadores desportivos: da inexistência de um instrumento estruturado à valorização dos resultados desportivos
}

CDD. 20.ed. 796.06

\section{Resumo}

Este estudo procurou compreender o processo e os critérios considerados na avaliação de desempenho dos treinadores pertencentes a nove clubes desportivos da Região Autônoma da Madeira, Portugal. Foi utilizada uma metodologia de carácter qualitativo, com recurso à análise documental da estrutura, dos recursos humanos dos clubes e a uma entrevista semiestruturada realizada aos diretores com responsabilidades na avaliação dos treinadores. Os resultados ilustram um processo de avaliação não estruturado, baseado em informações pouco sistematizadas e rigorosas. Os critérios de avaliação mais relevantes foram os resultados desportivos dos atletas, seguidos das competências de liderança e competências pessoais e sociais do treinador.

UnItERMos: Avaliação de desempenho; Treinadores; Dirigentes; Clubes desportivos.

\section{Introdução}

A avaliação de desempenho dos recursos humanos representa um instrumento que contribui para a melhoria da eficácia e eficiência dos processos de gestão de uma organização desportiva (TAYLOR, Doherty \& McGraw, 2008). Por exemplo, controlar e tomar decisões acerca da distribuição de responsabilidades, atribuir gratificações e prêmios de progressōes na carreira dos funcionários, bem como organizar ações de formação, são algumas das incumbências inerentes à administração das organizaçôes, que podem ser facilitadas através dos dados recolhidos no processo de avaliação de desempenho.

Ao utilizarem sistemas de avaliação de desempenho estruturados, isto é, devidamente definidos, regulados e assumidos pelos colaboradores de forma sistemática e utilitária, os clubes desportivos poderão aumentar o comprometimento dos funcionários e potenciar algumas das suas forças e competências, tendo em vista a melhoria contínua da sua performance. MACLEAN (2001) alerta para a importância de se avaliar os recursos humanos das organizaçôes, quer sejam desportivas ou não, salientando que estes são o seu mais importante recurso. Nem mesmo um funcionamento baseado na utilização de tecnologias sofisticadas e inovadoras, que tornam mais eficiente a realização de várias tarefas, poderá ter sucesso, se a gestão e avaliação do desempenho dos colaboradores não for prática corrente.

Segundo Gilbert e Trudel (2004), a avaliação de desempenho dos treinadores é ainda uma prática de gestão pouco consolidada nos clubes desportivos. Os avaliadores tendem a discriminá-la ou a utilizar sistemas de avaliação pouco rigorosos e fiáveis, segundo os quais as vitórias e as derrotas se assumem como principal critério de avaliação.

No sentido de alterar esta tendência, vários investigadores (CÔTÉ, Yardley, HaY, SEDGWICK \& BAKER, 1999; Cunningham \& Dixon, 2003; Feltz, 1999; Maclean \& Chelladurai, 1995; Mallet \& Côté, 2006), através das suas pesquisas, têm contribuído para uma melhor definição dos critérios, tornando a avaliação do desempenho do treinador um processo mais justo e imparcial.

MacLean e Chelladurai (1995), com recurso a uma vasta pesquisa bibliográfica, elaboraram um modelo que avalia o desempenho do treinador em
*Departamento de Educação Física, Universidade da Madeira - Portugal.

${ }^{*}$ Centro de Investigação em Desporto, Saúde e Desenvolvimento Humano - Portugal.

***Unidade de Investigação, Instituto Politécnico de Santarém - Portugal. 
três grandes dimensões: fatores comportamentais de produto; fatores comportamentais de processo diretamente relacionados com a tarefa; fatores comportamentais de processo indiretamente relacionados com a tarefa. Cada uma das três dimensōes foi dividida em duas, dando origem às seis subcategorias seguintes: resultados de equipe; resultados pessoais do treinador; comportamentos diretamente relacionados com a tarefa; comportamentos indiretamente relacionados com a tarefa; funções de natureza administrativa; comportamentos de relaçôes públicas.

Os autores contribuíram, assim, para uma definição mais clara das categorias, onde a avaliação de desempenho do treinador deveria recair. Contudo, referem que a validação do seu modelo, apenas contemplou as percepçóes dos treinadores e administradores. Por essa mesma razão, recomendam a realização de mais estudos que permitam também aferir as perceçōes dos atletas e dos media, tornando a aferição deste fenómeno mais abrangente.

Também CÔTÉ et al. (1999) desenvolveram a escala de comportamento do treinador desportivo, procurando mostrar que o trabalho do treinador deve ser avaliado nos seguintes domínios: planejamento do treino e competição; preparação mental dos atletas (controle da pressão, concentração e confiança); preparação das suas capacidades técnicas; relaçôes pessoais que estabelece com os atletas e demais agentes desportivos; estratégias utilizadas em competição.

Mais tarde, Cunningham e Dixon (2003), reconhecendo que todos os modelos desenvolvidos até então comportavam algumas limitaçôes, propuseram uma teoria que faz interface entre as teorias mais conservadoras e as mais recentes. As primeiras direcionam a sua gestão para a estratégia, estrutura e ambiente organizacional, enquanto as segundas veem a capacitação das pessoas como principal fator de desenvolvimento.

Contrariamente aos estudos referidos anteriormente, estes investigadores consideraram a natureza multinível das organizaçôes, ou seja, a multiplicidade de fatores que poderão intervir na avaliação de desempenho do treinador profissional. Advogam que não se pode dissociar o trabalho do treinador do trabalho da equipe, porquanto existe uma interdependência entre ambos. Como tal, propuseram um sistema de avaliação que tanto abarca o desempenho do treinador como o da equipe, em seis dimensões distintas: resultados desportivos da equipe; resultados acadêmicos da equipe; comportamento ético dos atletas; responsabilidade da escolha do atleta a ser contratado face às possibilidades financeiras do clube; recrutamento de atletas com qualidade; satisfação do atleta.
Apesar de não existir unanimidade por parte dos diversos investigadores, quanto às categorias sobre as quais deverá recair a avaliação do desempenho do treinador, parece haver um consenso generalizado quanto ao fato de a mesma não se poder restringir unicamente às conquistas desportivas e opiniōes públicas. Mais, a atividade do treinador é demasiado complexa para ser analisada só a partir dos resultados desportivos. Ela está dependente de vários fatores, como por exemplo: a missão específica do treinador e do próprio clube, o escalão etário dos atletas e a sua fase de aprendizagem, o nível competitivo em que estão envolvidos e ainda o contexto onde o treinador desenvolve o seu trabalho.

Em concordância com o pressuposto no parágrafo anterior e particularizando a avaliação de desempenho de treinadores de jovens, MALLET e CÔTÉ (2006) alertam para o fato de a inexperiência dos jogadores, as lesóes ou doenças, o estado maturacional e as capacidades técnicas não serem variáveis controladas pelo treinador.

Os estudos desenvolvidos por TAYLOR e MCGRAW (2006) demonstram que as organizações que adotam estratégias e medidas estruturadas na gestão de recursos humanos têm melhores resultados ao nível da prestação dos colaboradores, do que aquelas que o fazem de forma pouco ou nada estruturada.

No entanto, é fundamental que a estratégia definida pelo clube esteja em consonância com os objetivos e critérios utilizados na avaliação de desempenho. Assim, um clube cuja missão esteja direcionada para a formação de jovens no domínio psicológico, social e físico, deverá aferir se efetivamente os atletas melhoraram o seu comportamento a esse nível e em momento algum poderá sobrevalorizar o rendimento desportivo dos atletas na determinação do grau de realização do trabalho do treinador (TAYLOR, Doherty \& McGraw, 2008).

$\mathrm{O}$ estudo apresentado pretende conhecer como se processa a avaliação de desempenho dos treinadores que exercem funçôes nos clubes desportivos da Região Autônoma da Madeira (RAM), pelo que se direcionou a pesquisa no sentido de alcançar os seguintes objetivos:

- Contextualizar a avaliação de desempenho dos clubes, a partir da missão e das finalidades preconizadas pelos mesmos;

- Identificar qual o vínculo dos treinadores aos clubes;

- Aferir se a avaliação de desempenho dos treinadores é prática corrente e estruturada no seio da gestão dos recursos humanos do clube; 
- Identificar os instrumentos e critérios de avaliação de desempenho mais utilizados e valorizados;
- Apurar quais os dirigentes desportivos com responsabilidades na avaliação de desempenho do treinador.

\section{Decisões metodológicas}

\section{Grupo de estudo}

Dada a natureza do estudo (qualitativa), cuja pretensão recaiu na coleta de informaçôes profundas e detalhadas acerca do tema abordado, a representatividade da amostra não foi considerada. Neste sentido, entre todos os clubes desportivos existentes na RAM, apenas foram selecionados aqueles que reuniam, simultaneamente, as seguintes condições: número de atletas federados inscritos igual ou superior a 300 e pelo menos cinco anos de existência.

Após uma consulta da demografia federada, emanada pelo Instituto do Desporto da RAM, referente à época desportiva 2008-2009, verificou-se que 11 clubes cumpriam estes requisitos. Destes, dois não mostraram disponibilidade para colaborar no estudo, daí que os dados recolhidos sejam respeitantes a nove clubes desportivos.

\section{Instrumento de pesquisa}

A coleta de informação baseou-se na aplicação de uma entrevista semi-estruturada a nove indivíduos, com responsabilidades na gestão e avaliação dos treinadores dos clubes supracitados e na análise de documentação que explicava a estrutura organizacional do clube: cargos e funçóes e o número de treinadores existentes nas diferentes modalidades. Três clubes facultaram ainda o relatório elaborado pelo treinador sobre a avaliação da prestação dos atletas/equipe em competição.

\section{Guia da entrevista}

O guia da entrevista foi construído com base na análise conceitual de artigos bibliográficos enquadrados na temática de estudo e, posteriormente, validado por especialistas na área do treino e gestão de recursos humanos. A primeira parte da entrevista contemplou questôes direcionadas para o conhecimento da estrutura organizacional do clube, nomeadamente a dimensão, a missão, a distribuição de cargos e a natureza profissional dos treinadores. As respostas a estas questôes serviram para verificar a congruência entre as variáveis inerentes ao processo de avaliação do treinador e os objetivos que a organização preconizava.

Numa segunda parte, o objetivo central foi dissecar as questôes relacionadas com os critérios e procedimentos de avaliação de desempenho do treinador. Os resultados emanados foram imprescindíveis para determinar o grau de estruturação desta prática ao nível do clube e, desta forma, compreender se as reais competências do treinador são ou não valorizadas. Por fim, pretendia-se identificar as competências do avaliador.

\section{Procedimentos de aplicação da entrevista e participantes}

A aplicação da entrevista decorreu segundo as recomendações metodológicas de RUQUOY (2005), Gratton e Jones (2004) para as ciências sociais.

Numa primeira fase, estabeleceu-se um contato prévio com os entrevistados, no sentido de anunciar que se iria enviar um convite a pedir a sua colaboração. Procedeu-se, então, ao envio (e-mail) de um documento explicativo normalizado, onde se davam a conhecer os objetivos da investigação e da entrevista, a duração da mesma, garantia da confidencialidade dos dados, anonimato dos entrevistados e dos respetivos clubes. Após uma autorização e consentimento formal, por parte dos entrevistados, foi marcada uma data para a realização das entrevistas que decorreram entre outubro e dezembro de 2009 , tendo estas sido registadas através de um gravador de voz áudio.

\section{Tratamento da informação}

As entrevistas foram transcritas na íntegra e analisadas posteriormente, através de um processo de categorização dos dados (BARDIN, 2009; RUQUOY, 2005).

O processo de sistematização da informação obtida contemplou os dois tipos de categorização: "a priori" e "a posteriori". Para analisar as respostas diretamente relacionadas com a avaliação de desempenho, as categorias de análise foram definidas aprioristicamente de acordo com os modelos e escalas de avaliação da eficácia dos treinadores, defendidos pelos autores de referência (Cunningham \& Dixon, 2003; MacLEan 
\& Chelladurai, 1995; Mallet \& Côté, 2006). Assim, surgiram as seguintes categorias: resultados desportivos, competências de liderança, competências pessoais e sociais, competências formativas e humanas, competências técnico-táticas do treinador.

Já no que concerne à organização das unidades de registro resultantes da pergunta alusiva à missão do clube, foram-se estabelecendo as categorias, à medida que se analisavam os dados (categorização "a posteriori”), consoante os critérios apresentados:

- Função social e de formação geral dos praticantes: inserem-se nesta categoria todas as referências à missão do clube direcionadas para a formação integral dos jovens;

- Resultados desportivos: referências às conquistas ou classificações desportivas assumidas como prioridade do clube;

- Comércio: missão direcionada para fins lucrativos do ponto de vista financeiro.

Para cada uma das categorias, foram contabilizadas as frequências absolutas de cada unidade de registo, permitindo assim aferir a relevância e supremacia de umas categorias em relação às outras.

\section{Resultados}

\section{A missão dos clubes}

A missão de todos os clubes entrevistados converge para a formação social, educativa e desportiva dos atletas. Os resultados obtidos apontam para uma hegemonia da sub-categoria "Função social e de formação", a qual congregou nove unidades de registo que contemplam conceitos alusivos à formação dos atletas nos vários domínios (intelectual, físico e social). Em segundo plano, aparecem os resultados desportivos (três unidades de registro) e a vertente comercial, com uma unidade de registro.

TABELA 1 - Frequência de subcategorias inerentes à missão.

\begin{tabular}{|c|c|c|}
\hline $\begin{array}{l}\text { Categoria } \\
\text { Missão }\end{array}$ & Dados & Frequência \\
\hline $\begin{array}{l}\text { Função social } \\
\text { e de } \\
\text { Formação geral } \\
\text { dos praticantes }\end{array}$ & $\begin{array}{l}\text { E1: (...)a função principal do clube, é uma função social que é ocupar a } \\
\text { juventude...; } \\
\text { E2: incutir-lhes hábitos de exercício físico e bons estilos de vida.; } \\
\text { E3: (...) permitir que a juventude tenha um determinado espaço onde possa } \\
\text { ser organizada e dinamizada a prática desportiva.; } \\
\text { E4: (...) servir socialmente a própria cidade, contribuindo para a formação } \\
\text { global dos jovens da terra.; } \\
\text { E5: A missão do clube é direcionada para a formação geral dos jovens...; } \\
\text { E6: Nós temos, para além da nossa missão social e desportiva...; } \\
\text { E7: (...) uma vertente direcionada para o contexto social. } \\
\text { E8: (...) tem como missão o fomento e prática de atividades de natureza des- } \\
\text { portiva, social, cultural e recreativa (...) satisfazer as necessidades intelectuais, } \\
\text { de cultura física, desportiva e de lazer e o espírito de solidariedade, fraternida- } \\
\text { de social e respeito pelo valor da ética desportiva (...); } \\
\text { E9: (...) temos o nosso papel social na formação das diferentes fases da vida da } \\
\text { nossa juventude. }\end{array}$ & 9 \\
\hline $\begin{array}{l}\text { Resultados } \\
\text { Desportivos }\end{array}$ & $\begin{array}{l}\text { E2: Como objetivo secundário pretende-se alcançar resultados desportivos na } \\
\text { equipa sénior de futebol e outras modalidades.; } \\
\text { E5: (...) mas não descurando os resultados desportivos.; } \\
\text { E7: (...) uma vertente profissional baseada nos resultados desportivos da alta } \\
\text { competição.; }\end{array}$ & 3 \\
\hline Comércio & $\begin{array}{l}\text { E6: (...) Temos também uma missão quase que dimensionada para o lado do } \\
\text { lazer versus comércio, de forma a equilibrar a nossa atividade geral. }\end{array}$ & 1 \\
\hline
\end{tabular}




\section{Grau de profissionalização dos treinadores e dirigentes}

Os treinadores são, na sua larga maioria, colaboradores sem qualquer tipo de contrato profissional. Pela interpretação das respostas dos responsáveis pela avaliação dos treinadores, constatou-se que estes têm um vínculo aos clubes que pode ser considerado precário, uma vez que é baseado fundamentalmente em acordos de cooperação com uma contrapartida financeira ("gratificação"). Apenas uma minoria tem vínculo profissional aos clubes. Apresentam-se alguns exemplos de frases proferidas pelos entrevistados:

E1: O clube tem 12 treinadores que recebem uma pequena gratificação.

E3: O clube conta com 25 treinadores que, apesar de não serem profissionais, recebem uma gratificação...

E6: O clube conta com 62 treinadores, dos quais 12 são profissionais a tempo inteiro e os restantes 50, embora não sendo profissionais, recebem uma gratificação...

\section{Da inexistência de instrumentos de avaliação de desempenho à prática informal e não estruturada}

A análise de conteúdo das entrevistas revelou que não existe um sistema ou modelo de avaliação de desempenho do treinador estruturado e assumido pelos clubes, de forma a conferir rigor e objetividade a esta prática:

E2: São instrumentos que não são nada formais!

Tem que ver com salários, tem que ver com qualidades humanas, tem que ver com o próprio desempenho desportivo... ou a afirmação do E3: Não existe nenhum instrumento concreto para fazer essa avaliação. (...) há sempre uma preocupação de acompanhar não só a atividade do treinador, mas prontos(...).

Estas constatações são extensíveis a todos os clubes que fazem parte do grupo de estudo. Contudo, dos nove clubes participantes no estudo, verificouse que dois deles, apesar de assumirem a prática da avaliação de desempenho dos treinadores enquanto processo não formal, observam o comportamento do treinador nos treinos e nas competições. Tal como se pode confirmar a partir dos seguintes excertos das entrevistas:

E1: Não existe nenhum instrumento de avaliação de desempenho. A avaliação é feita informalmente através da observação in loco dos treinos e jogos. (...) vamos, no mínimo, uma vez por semana ao campo, assistimos a treinos, falamos com as pessoas...

E5: A avaliação é feita através da observação dos jogos! (...) estão a haver dois jogos de diferentes escalóes, como se sucedeu ontem. Eu estava a ver um jogo e o outro coordenador ficou aqui a ver o outro, depois falamos um bocadinho e tomamos aquelas notas que achamos necessárias para falar com os técnicos.

Houve ainda mais dois entrevistados que disseram avaliar os treinadores com base em relatórios:

E6: A mim compete-me única e exclusivamente receber os relatórios de cada um dos departamentos e avaliar aquilo que foi o seu desempenho ao longo duma época desportiva (...), compete a cada um dos departamentos fazer a avaliação dos seus treinadores.

E9: (...) todos esses treinadores vão chegar ao fim da época (...) apresentam um relatório trimestral (...), que não vai ser bem um instrumento de avaliação, mas que vai ajudar a avaliação, porque a avaliação é feita semanalmente.

\section{Critérios de avaliação do treinador}

Apesar de não fazer parte, enquanto processo formal, objetivo e estruturado, a avaliação de desempenho integra os processos de gestão de todos os clubes. Nessa medida, identificaram-se os resultados desportivos como o principal critério de avaliação, tendo sido assumido, por alguns entrevistados, que estes poderão ser determinantes para a continuidade do treinador. Saliente-se, apenas, que, à medida que se vai descendo no escalão desportivo e no nível competitivo, vai-se aumentando a tolerância aos maus resultados.

Como segundo critério mais valorizado, foram apontadas as competências de liderança do treinador, nomeadamente, a sua capacidade para motivar os atletas, principalmente os mais novos, ao ponto de os fidelizar ao clube.

$\mathrm{O}$ terceiro critério mais relevante diz respeito às competências pessoais e sociais, que representam a capacidade do treinador para comunicar e interagir com os atletas, colegas, dirigentes e outros elementos ligados ao clube. Nesta medida, o clima das relações estabelecidas, segundo os entrevistados, influencia também a decisão final acerca do desempenho do treinador.

A TABELA 2 sistematiza os principais critérios a ter em consideração na avaliação de desempenho dos treinadores. 
TABELA 2 - Critérios de avaliação do treinador.

\begin{tabular}{lcc}
\hline $\begin{array}{c}\text { Parâmetros de } \\
\text { avaliação }\end{array}$ & Dados & Frequência \\
\hline
\end{tabular}

Resultados
desportivos
Competências
de liderança:
motivação e
fidelizaçáo dos
atletas

E1: (...) os resultados contam quer se queira, quer não, temos de ver os resultados (...)

E2: (...) os resultados desportivos também são importantes (...) embora o objectivo não seja ganhar primeiro lugar, seja a formação, mas isso também conta E3: Nós acabamos por fazer quase uma avaliação pelos resultados desportivos ao longo do ano...Isso é a verdade dos fatos.

E4: (...) não vou negar, embora que o resultado seja importantíssimo para todos eles, é de uma forma crescente que a importância dos resultados acaba por aparecer na avaliação dos treinadores(...) Portanto, a importância dos resultados na equipe senior acaba por ter um peso maior..."

E7: Primeiro para o comum dos adeptos, o desempenho faz-se pelos resultados.

E1: Um treinador dos escalōes juniores ou juvenis ou iniciados, que estão naquela casa há quatro ou cinco anos, que tem sempre uma média de 18 a 20, 22 jogadores por treino (...) tem praticamente continuidade garantida. E9: (...) depois podemos ter que falar na situação da liderança que é fundamental em qualquer dos escalóes (...)

E7: (...) Nestes escalōes além dos resultados são valorizados critérios de liderança e interação com outras estruturas do clube...

E8: (...) Portanto ver os atletas motivados, o gosto pelo treino, o gosto pela competição, a assiduidade nas presenças.

E1: Um treinador (...) que tem um bom relacionamento com os atletas e com os pais (... ) tem praticamente continuidade garantida.

Competências E3: (...) para além dos resultados desportivos, também o comportamento Pessoais e social que tem com os atletas...

Sociais E8: Acontece que é uma pessoa que em termos de relacionamento é um bocado conflituosa e falhou, por ai falhou, falhou completamente. E quando se falha a nível do relacionamento, naturalmente que isso reflete-se no rendimento.

E2: Evidentemente que a avaliação do desempenho não tem propriamente que ver com resultados desportivos, tem que ver com formação (...) qualidades humanas, de contato com (...) qualidades formativas propriamente ditas, especificamente desta profissão.

\section{Competências Formativas e Humanas}

Competências técnico-tácticas do treinador
E7: (...) passando para os outros escalōes, a tolerância relativamente aos resultados vai aumentando até porque se entende que há aí um espaço mais de formação e de socialização.

E6: (...) não é um clube que esteja obcecado pelos resultados, está mais obcecado pela sua formação, pela possibilidade de proporcionar aos atletas, condições de desenvolvimento tanto técnico como humano.

E5: Há os princípios de jogo, há os conteúdos dos diferentes escalóes, essas coisas todas que estão a ser a minha base de preocupação com os técnicos. E9: Nos aspectos técnicos-tácticos existe a capacidade de dar resposta a uma situação de jogo rapidamente, uma capacidade de leitura de jogo mais rápida, introdução de elementos a nível do treino que sejam motivadores, que sejam evolutivos.

E9: (...) E depois, outro item que eu julgo que tem uma grande importância é a ambição, mais do que a ambição, a paixão por estar no treino e a outra que será ter uma conceção unitária do clube. 


\section{Avaliadores}

Os dados indicam que não existe um único responsável pela avaliação de desempenho dos treinadores, apesar de, em última instância, ser o presidente da direção a tomar a decisão final. A avaliação é realizada, primordialmente, pelos coordenadores de modalidade ou coordenadores gerais. Quando não existe um coordenador, são os próprios presidentes de direção que acompanham e observam o desempenho dos treinadores nos treinos e competiçōes e, a partir desse registro, tiram as suas ilaçôes, podendo também ser influenciados pelas percepções de outros elementos da direção, de treinadores dos escalóes superiores ou, até mesmo, pelos pais dos atletas (nos escalóes inferiores). Isto é o que acontece no clube do "E1", apresentando-se a seguinte declaração como exemplo: "Tanto eu como o meu vice-presidente vamos, no mínimo, uma vez por semana ao campo, assistimos a treinos, falamos com as pessoas..."

Realce-se que, no clube do "E2", a avaliação de desempenho é feita interpares, isto é, os treinadores autoavaliam-se e depois trocam impressōes com outros colegas.

Definir objetivos para o clube e para o treinador deverá ser considerado como o primeiro passo de qualquer processo de avaliação. Nesse sentido, procurou-se descobrir se existiam reuniōes entre o avaliador e o avaliado, tendo em vista a definição desses mesmos objetivos e qual a sua periodicidade. Apenas dois dos entrevistados assumiram, claramente, uma definição de objetivos partilhados com os treinadores no início da época desportiva, mas a maioria (seis) considerou a avaliação de desempenho uma prática permanente e contínua, ainda que realizada informalmente através de conversas ocasionais.

\section{Discussão}

Os resultados decorrentes das entrevistas remetem para a avaliação de desempenho dos treinadores como sendo um procedimento pouco estruturado. Nenhum dos nove dirigentes entrevistados afirmou utilizar instrumentos válidos, confiáveis e rigorosos para avaliar o desempenho dos treinadores do seu clube. Baseavam-se essencialmente na observação informal do comportamento do treinador nos treinos e nos jogos, com destaque para os resultados desportivos e competências de liderança, como principais critérios de avaliação.

O baixo nível de profissionalização, quer dos treinadores quer dos dirigentes, poderá ser uma questão de relevo no contexto da avaliação de desempenho, uma vez que, segundo TAYLOR e MACGRAW (2006), parece existir uma relação entre o nível de profissionalização e a utilização de sistemas formais de medição do desempenho. Ao verificar-se que, na sua quase totalidade, os clubes são dirigidos por voluntários, que, por sua vez, também "contratam" treinadores a tempo parcial em troca de pequenas compensaçóes financeiras, pode-se estar a assistir a uma falta de comprometimento com a organização, deixando para segundo plano as exigências associadas ao cargo que assumem e desvirtuando, assim, a avaliação de desempenho.

Como tal, os resultados da investigação sobre o papel do dirigente de topo (voluntário) e o papel gestor desportivo profissional sugerem a adoção de práticas de gestão mais racionais e estruturadas e uma relação de cooperação entre dirigentes do "board" e os gestores profissionais (Cuskelly, Hoye \& Auld, 2006; Soares, Correia \& Rosado, 2010; Hoye, 2007; Hoye \& Cuskelly, 2003).

Os resultados também confirmaram que a avaliação dos treinadores tem como critério maior os resultados desportivos. Não se pode dizer que este resultado seja surpreendente, até porque a literatura é consensual ao identificar que, na ausência de um sistema de avaliação, as vitórias e derrotas são, na maior parte dos casos, o único parâmetro analisado para avaliar a performance do treinador (GILBERT \& Trudel, 2004; MacLean, 2001). Por outro lado, os estudos de BARBER e ECKRICH (1998) comprovaram que, quando são utilizados sistemas de avaliação, a categoria "program success", que diz respeito às vitórias alcançadas nas competições em que o atleta/equipe participa, tende a ser desvalorizada. No entanto, há uma evidência deste estudo que é coincidente com os resultados obtidos por BARBER e ECKRICH (1998): as conquistas desportivas perdem força à medida que o nível competitivo diminui.

Os dados apurados parecem evidenciar uma incongruência entre a missão assumida pelos clubes e os critérios mais valorizados na avaliação dos treinadores. Isto porque todos os clubes enalteceram como razão da sua existência uma função social esbatida na formação integral dos atletas, daí que se torne incompreensível a supremacia dos 
resultados alcançados em termos desportivos, comparativamente com outros critérios de avaliação. Este resultado poderá levantar uma questão: até que ponto os treinadores conseguem conciliar a pressão da obtenção dos resultados desportivos com a missão social e formativa assumida pelos clubes? Esta questão sugere mais investigação sobre os resultados obtidos pelos treinadores, ao nível dos escalóes etários de formação (jovens em aprendizagem) e das competências sociais e desportivas dos seus atletas. Pois, a avaliação de desempenho tem de contextualizar os objetivos e o papel específico do treinador face ao grupo com quem está a treinar. Segundo Mallett e Côté (2006), durante o processo de avaliação da eficácia do treinador, não se pode dissociar o contexto específico em que as relaçôes treinador-atleta se efetivam.

Como segundo critério mais valorizado para determinar o grau de eficácia do treinador, os dados do estudo indicaram as competências de liderança: capacidade de motivar os praticantes ao ponto de os fidelizar o mais possível ao clube. Os clubes só existem porque há atletas a querer praticar a(s) sua(s) modalidade(s). Nesta medida, é compreensível que a capacidade do treinador para reter os praticantes seja valorizada. Os níveis de assiduidade e de empenhamento dos atletas poderão, também, constituir-se como indicadores indiretos do seu desempenho. E, se assim deve ser, então a assiduidade e empenhamento dos jovens nos treinos deve ser passível de ser medida, de forma a servir como critério objetivo e válido, no processo de avaliação de desempenho do treinador.

\section{Conclusões e recomendações}

Como conclusão geral deste estudo, poder-se-á dizer que a avaliação de desempenho dos treinadores é um processo pouco consolidado nas práticas de gestão dos clubes desportivos. Para além disso, está desajustada com a verdadeira razão da existência dos mesmos e não contempla critérios de avaliação que estejam em conformidade com as atribuições específicas de cada treinador. Sugere-se, então, que os dirigentes (avaliadores) procurem ser coerentes e rigorosos nas avaliações que fazem, ao invés de colocarem as vitórias e derrotas como elementos diferenciadores do desempenho do treinador. Assim, urge definir critérios de avaliação que se coadunem com o perfil de competências do treinador.

Importa considerar que um sistema de avaliação de desempenho não poderá ser aplicado
As relações pessoais e sociais que o treinador estabelece com os atletas, com os seus pares, com os pais e com os dirigentes, foram também critérios apontados como relevantes na avaliação de desempenho. Porém, há ainda a destacar outros aspectos que, apesar de terem sido pouco enaltecidos, são considerados, segundo a literatura do desporto de alta competição e de nível profissional (MACLEAN \& Chelladurai, 1995), imprescindíveis na avaliação de desempenho: as competências de planejamento, de organização dos treinos e competições; os conhecimentos técnico-táticos; as competências de gestão.

No que concerne ao responsável pela avaliação do desempenho, o coordenador geral ou de modalidade desportiva é aquele que assume uma maior preponderância, apesar de ser o Presidente da Direção do clube que detém a autoridade máxima e assume o poder de contratação ou destituição do treinador. Se a observação dos jogos e competições constitui um dos meios privilegiados adotados pelos clubes, para recolher dados sobre a prestação dos treinadores, então é necessário definir as competências de direção e de liderança dos colaboradores mais diretos, quer os de natureza voluntária, quer os de natureza profissional. Acrescente-se, ainda, que a avaliação do desempenho dos treinadores só faz sentido se for frutuosa para ambas as partes, tanto para o treinador como para o clube, mas para isso é fundamental estabelecer objetivos concretos entre ambos. Enquanto a avaliação não for entendida como um processo cíclico e participado, nunca se poderão alcançar bons resultados.

uniformemente a treinadores com diferentes papéis. Certamente que o papel de um treinador de jovens, inserido num processo de iniciação desportiva, não será igual ao de um treinador que trabalha com atletas/equipes de um nível competitivo mais avançado. Nesta medida, parece óbvio que deverá haver uma consciencialização, por parte dos clubes e dos avaliadores, para este fato.

Se todo o processo for bem conduzido, irão beneficiar ambas as partes: os clubes, que tendo informaçōes fidedignas poderão tomar decisões mais justas relativamente às compensaçôes, progressōes ou promoçōes do treinador, e os próprios treinadores, que, por sua vez, ficam também a conhecer as suas forças e as suas fraquezas. 


\begin{abstract}
Performance appraisal of sports coaches: from the lack of a structured instrument to the enhancement of sports results

This study aims to understand the process and the criteria evolved in the performance appraisal of coaches of nine sport clubs in the Autonomous Region of Madeira, Portugal. The methodology used was based on a documentary analysis of the human resources of the institution and it was carried out a semi-structured interview done to the directors responsible for the performance appraisal of the coaches. The results show a less structured evaluation process, based on poor and inaccurate organization data. The most relevant criteria in the evaluation process were the sports scores of athletes, followed by the leadership skills and personal and social skills of the coach.
\end{abstract}

UnITERMs: Performance appraisal; Coaches; Sport directors; Sport clubs.

\title{
Referências
}

BARBER, H.; ECKRICH. J. Methods and criteria employed in the evaluation of intercollegiate coaches. Journal of Sport Management, Champaign, v.12, p.301-22, 1998.

BARDIN, L. Análise de conteúdo. Lisboa: Edições 70, 2009.

CÔTÉ, J.; YARDLEY, J.; HAY, J.; SEDGWICK, W.; BAKER, J. An exploratory examination of the coaching behavior scale for sport. Avante Research Note, Gloucester, v.5, n.2, p.82-92, 1999.

CUNNINGHAM , G.; DIXON, M. New perspectives concerning performance appraisals of intercollegiate coaches. National Association of Physical Education in Higher Education, Champaign, v.55, p.177-92, 2003.

CUSKELLY, G.; HOYE, R.; AULD, C. Working with volunteers in sport: theory and practice. London: Routledge, 2006. FELTZ, D.L.; CHASE, M.A.; MORITZ, S.E.; SULLIVAN, P.J. A conceptual model of coaching efficacy: preliminary investigation and instrument development. Journal of Educational Psychology, Washington, v.91, p.675-776, 1999.

GILBERT, W.; TRUDEL, P. Analysis of coaching science research published from 1970-2001. Research Quarterly for Exercise and Sport, Washington, v.75, p.388-99, 2004.

GRATTON, C.; JONES, I. Research methods for sport studies. London: Routledge, 2004.

HOYE, R. Commitment, involvement and performance of voluntary sport organisation board members. European Sport Management Quarterly, London, v.7, n.1, p.109-21, 2007.

HOYE, R.; CUSKELLY, G. Board-executive relationships within voluntary sport organisations. Sport Management Review, Bundoora, v.6, p.53-74, 2003.

MacLEAN, J. Performance appraisal for sport and recreation managers. Champaign: Human Kinetics, 2001.

MacLEAN, J.; CHELLADURAI, P. Dimensions of coaching performance: development of a scale. Journal of Sport Management, Champaign, v.9, p.194-207, 1995.

MALLET, C.; CÔTÉ, J. Beyond winning and losing: guidlines for evaluating high performance coaches. The Sport Psychologist, Champaign, v.20, p.213-21, 2006.

RUQUOY, D. Situação de entrevista e estratégia do entrevistado. In: ALBARELLO, L.; DIGNEFFE, F.; HIERNAUX, J.P.; MAROY, C.; RUQUOY, D.; SAINT-GEORGES, P. Práticas e métodos de investigação em ciências sociais. 2. ed. Lisboa: Gradiva, 2005. p.84-116.

SOARES, J.; CORREIA, A.; ROSADO, A. Political factors in the decision making process in the voluntary sports associations. European Sport Management Quarterly, London, v.10, n.1, p.5-29, 2010.

TAYLOR, T.; DOHERTY, A.; McGRAW, P. Managing people in sport organizations. Oxford: Butterworth-Heinemann, 2008. TAYLOR, T.; McGRAW, P. Exploring human resource management practices in nonprofit sport organisations. Sport Management Review, Bundoora, v.9, p.229-51, 2006. 
SOARES, J .A.P.; ANTUNES, H.R.L. \& RODRIGUES, J .J.F.

ENDEREÇO

Hélio Antunes

Universidade da Madeira

Campus da Penteada

9000-390 - Funchal - Madeira - PORTUGAL

Recebido para publicação: 28/ 09/ 2010

1a. Revisão: 22/ 03/2011

2a. Revisão: 26/07/2011

e-mail: h.antunes@uma.pt

Aceito: 04/ 08/2011

440 • Rev. bras. Educ. Fís. Esporte, São Paulo, v.25, n.3, p.431-40, jul./ set. 2011 